\title{
CAPM EM ESTUDOS BRASILEIROS: UMA ANÁLISE DA PESQUISA
}

\section{CAPM IN BRAZILIAN STUDIES: AN ANALYSIS OF THE RESEARCH}

\author{
Elisson Alberto Tavares Araújo ${ }^{a}$; Victor do Carmo Oliveira ${ }^{b}$; \\ Wendel Alex Castro Silva ${ }^{c}$ \\ a Pesquisador da Faculdade Novos Horizontes, FNH e da Fundação Dom Cabral, FDC \\ Mestre em Administração pela Faculdade Novos Horizontes, FNH \\ Belo Horizonte, MG - Brasil; E-mail: elisson.araujo@unihorizontes.br \\ ${ }^{b}$ Professor da Faculdade ASA \\ Mestre em Administração pela Faculdade Novos Horizontes, FNH \\ Brumadinho, MG-Brasil; E-mail: cvictordocarmo@yahoo.com.br \\ ${ }^{c}$ Professor Titular da Faculdade Novos Horizontes, FNH \\ Doutor em Administração pela Universidade Federal de Lavras, UFLA \\ Belo Horizonte, MG -Brasil: E-mail: wendel silva@unihorizontes br
}

Resumo

Nas últimas décadas, o modelo de precificação de ativos financeiros CAPM (Capital Asset Pricing Model) tem se sido um tema recorrente nos estudos em contabilidade e finanças, também no Brasil. Com o intuito de conhecer suas principais características metodológicas e constatações, realizou-se um levantamento dos artigos acadêmicos abordando o CAPM e variantes no país, entre 1997 e 2008, apresentados nos EnANPADs e em periódicos nacionais,. A estatística descritiva foi utilizada nas análises. Constatou-se que, em quase $1 / 3$ dos trabalhos houve comparações do CAPM com outros modelos. A versão convencional foi a mais utilizada, e os seguintes perfis foram identificados nesses artigos: 1) naqueles que confirmaram a efetividade da teoria: boa parte informou os dados de modo incompleto; prevaleceram as análises cross-section; o Ibovespa foi a proxy da carteira de mercado mais utilizada; a SELIC foi a proxie do ativo livre de risco preferida; os períodos de análise entre um e três anos predominaram, 2) naqueles que a refutaram: a maioria dos dados estavam incompletos; foco nas análises cross-section, e nos testes em períodos de um a três anos; e o Ibovespa e o CDI foram as proxies mais aplicadas. Além disso, o IGP-DI foi o deflacionador preponderante, muitos não indicaram o tipo de ação utilizada, e os ativos individuais tiveram preferência nos testes empíricos. Concluiu-se que o modelo tem sido satisfatório no país, apesar de alguns elementos utilizados na sua operacionalização não atenderem, exatamente, às premissas da teoria. Porém, devido às anomalias, o seu desempenho tem sido comparado com outros modelos, ou fatores que ampliem sua eficiência têm sido acrescentados.

Palavras-chave: Contabilidade e Finanças. Pesquisa sobre CAPM. Modelos de Precificação de Ativos.

\begin{abstract}
For the last decades, the Capital Asset Pricing Model (CAPM) has also been a recurring theme in studies in accounting and finance in Brazil. We have gathered national academic papers from 1997 to 2008 on the CAPM and variants, presented in EnANPADs and national journals, in order to study their main methodological characteristics and findings. Descriptive statistics were used in the analysis. Almost 1/3 of the work compared CAPM with other models. The conventional version was the most used one. The following characteristics were identified on these papers: 1) for those which had confirmed the effectiveness of the theory: much of the data reported were incomplete; cross-section analysis prevailed; Ibovespa was the most used proxy of the market portfolio; SELIC was the most preferred proxy of the risk free asset; study periods between one and three years prevailed, 2) for those that had rejected it: most data were incomplete; focus on the cross-section analysis; testing periods from one to three years; and Ibovespa and CDI were the most invested proxies. Furthermore, the IGP-DI was the predominant deflator, many didn't indicate the type of share used, and the individual assets were the ones preferred in the empirical tests. We concluded that the model has been satisfactory in the country, despite the failure of some elements to precisely comply with the premises of the theory. Due to the deficiencies, though, many researchers have compared its performance with other models or have added factors that improve their efficiency.
\end{abstract}

Keywords: Accounting and Finances; Research on CAPM; Asset Pricing Models. 


\section{INTRODUÇÃO}

A Moderna Teoria de Finanças tem como seus principais expoentes, Markowitz (1952 e 1959), Sharpe (1964), Modigliani e Miller (1958 e 1963) e Fama (1970 e 1991), os quais, a partir da década de 1950, formaram a sua base teórica por meio de contribuições que mudaram as concepções da "antiga" teoria de finanças, tornado-a mais dinâmica.

Essas contribuições proporcionaram importantes avanços - teóricos ou operacionais nas três grandes áreas de decisão em finanças: investimentos, financiamentos e distribuição de dividendos. Esta pesquisa insere-se no rol das decisões de investimentos, em que se estuda a aplicação do modelo CAPM - Capital Asset Pricing Model, para a predição e/ou explicação do retorno (rentabilidade) esperado pelos proprietários do capital.

Esse modelo teve como maior destaque Sharpe (1963 e 1964), que a partir das premissas de Markowitz (1959), contando com as contribuições de Tobin (1958), Treynor (1961), Lintner (1965), Mossin (1966) e Black (1972), revolucionou as premissas de finanças, ao traduzir, por intermédio de uma equação relativamente simples, a relação risco e retorno. Não obstante, passou a ser alvo de inúmeros testes empíricos por parte dos pesquisadores, a fim de avaliar sua validade prática. Com a constatação de algumas de suas anomalias (deficiências) a partir destes testes, a sua efetividade passou a ser questionada, visto que o poder explicativo do modelo não se mostrava satisfatório frente às análises. Isso levou os pesquisadores em contabilidade e finanças a buscarem soluções que ampliassem o fator explicativo do CAPM, o que resultou no surgimento de algumas variantes como o C-CAPM (conditional) e o D-CAPM (downside), entre outros, abarcando um maior número de variáveis e com melhor adequação aos pressupostos, tendo em vista a característica de cada mercado, o que permitia o aumento da eficiência de seu poder de explicação. Modelos como o Arbitrage Pricing Theory (APT) e o 3-Fatores de Fama e French também foram desenvolvidos. Mesmo assim, o CAPM é o mais utilizado para estimar o retorno de ativos, despertando o interesse dos pesquisadores em conhecê-lo melhor em diferentes contextos e circunstâncias.

Dentre as pesquisas que, nos últimos anos, abordaram o modelo CAPM, Raboni et al. (2008) testaram a estratégia de investimento em ações que tiveram crescimento nos últimos anos; Salmasi (2008) investigou a relação entre governança corporativa e o custo de capital próprio em companhias brasileiras; Mazer e Nakao (2008) examinaram a existência de relação entre o nível de transparência e o custo de capital próprio de companhias do Ibovespa; Piloto, Senra e Moreno (2008) desenvolveram uma nova fórmula para o cálculo do WACC; e Castro Silva et al. (2009) compararam empiricamente o CAPM na versão estática e na condicional.

Portanto, não se encontrou, dentre as pesquisas brasileiras identificadas, algum trabalho que apresentasse um levantamento das principais características metodológicas dos artigos que estudaram o CAPM e variantes, no mercado de capitais do país, com destacado desempenho nos últimos anos, bem como sinais de desenvolvimento a nível internacional.

A questão que norteia tal pesquisa é: Quais são as principais características metodológicas e constatações dos trabalhos que abordaram o CAPM e variantes, no Brasil, entre 1997 e 2008? 
Face à relevância do modelo, e ao desenvolvimento do mercado acionário nacional, este trabalho se propõe a fazer um levantamento dos artigos acadêmicos que abordaram o modelo CAPM e variantes, no Brasil, entre 1997 e 2008, nos EnANPADs (Encontros da Associação Nacional de Pós-graduação e Pesquisa em Administração) e em periódicos nacionais, para conhecer as principais características metodológicas e achados dos mesmos. Este trabalho enquadra-se como uma pesquisa da pesquisa acerca do modelo CAPM.

\section{REFERENCIAL TEÓRICO}

\subsection{O Modelo CAPM}

O trabalho clássico de Markowitz (1959), em que o retorno foi estudado como a diferença de log dos preços, permitiu o desenvolvimento do Modelo CAPM por Sharpe (1963 e 1964), o qual apresentou o cálculo do retorno na forma linear, e contou ainda com as contribuições de Tobin (1958), Treynor (1961), Lintner (1965), Mossin (1966) e Black (1972) para o aperfeiçoamento do Modelo, considerando haver um relacionamento linear entre risco (variância do retorno) e retorno (média da rentabilidade ou recompensa do ativo). Essa teoria de precificação de ativos teve tamanha importância para o campo das finanças modernas, que Sharpe foi laureado com o Prêmio Nobel de Economia em 1990.

O CAPM foi constituído e fundamentado nas premissas das teorias da utilidade e da hipótese da eficiência de mercado (COSTA Jr., MENEZES e LEMGRUBER, 1993), e considerava que, em situação de equilíbrio, a expectativa de retorno de um ativo seria igual ao retorno de um ativo livre de risco, somado a um prêmio pelo risco assumido, prêmio esse resultado da diferença entre o retorno da carteira de mercado e ativo livre de risco, ponderado pelo beta (coeficiente de risco sistemático), o qual é a medida de sensibilidade de risco da empresa (BRUNI, 1998).

Sharpe, Alexander e Bailey (1995) e Tomazoni e Menezes (2002) completam que o beta mensura a volatilidade dos retornos do ativo de forma relativa aos retornos do portfolio de mercado, portanto, é uma métrica de risco sistemático, não podendo ser extinto com a diversificação de ativos. Por meio do beta, pode-se estimar o risco total (diversificável + não-diversificável) de um ativo ou de portfolios, já que ele associa o risco sistemático (nãodiversificável ou conjuntural) ao não-sistemático (diversificável, não-sistêmico, único, específico ou idiossincrático), que pode ser eliminado com a diversificação de ativos. O beta é dado pela razão entre a covariância do retorno da ação da firma e da carteira de mercado, pela variância do retorno da carteira de mercado. Ele corresponde ao coeficiente angular da reta da regressão simples do CAPM, que é calculada por intermédio do retorno da ação da empresa em relação ao retorno da carteira de mercado. Sabendo-se que, a relação entre o risco do ativo e retorno exigido é linear, e se o beta for a métrica de risco apropriada, logo, quanto maior risco o ativo apresentar, proporcionalmente, maior será o retorno desejado pelo investidor. Securato (1996) conceitua que o risco sistemático é aquele determinado pelos sistemas político, econômico e social (variáveis macroeconômicas), e o risco não-sistemático é aquele inerente ao próprio ativo ou ao subsistema ao qual pertence (variáveis microeconômicas), não influenciando outros ativos e seus ambientes, como acontece com o outro risco.

Dessa maneira, esse modelo busca explicar o comportamento dos valores dos ativos e 
auxiliar na avaliação dos investimentos (AMARAL et al., 2004), tanto para ativos individuais como para portfolios. Ainda para os mesmos autores, as decisões financeiras mais importantes devem ser estudadas à luz da expectativa de retorno e de risco e dos efeitos dessa associação ao valor do ativo. Então, o CAPM é um modelo indicado para ser aplicado tanto nas decisões financeiras empresariais como de investidores (pessoas físicas). Para Tomazoni e Menezes (2002), o CAPM assume que os investidores são racionais e, portanto, a expectativa é que constituirão portfolios por meio de associações entre a taxa livre de risco e o portfolio de mercado. O grau de aversão a risco de cada investidor é que definirá a forma de alocar seus recursos, e o risco individual do ativo é aquele relativo ao portfolio de mercado, o qual será adequado ao portfolio do investidor.

Segundo Silva et al. (2009), essas são as versões convencionais (básicas ou estáticas) do modelo, pois se utilizam de projeções estáticas (constantes ou estacionárias) do beta, isto é, sem a alteração do risco sistemático no decorrer do tempo, o que se sabe não ser verdadeiro.

Para Bruni (1998), inicialmente, foram aplicados testes estatísticos das décadas de 1960 e 1970 que confirmaram a efetividade do modelo. Mas, em pesquisas no fim da década de 1970, além do beta, foram sugeridas outras variáveis significantes estatisticamente em relação ao retorno dos ativos, quais sejam: tamanho da empresa, endividamento, book-to-value, bookto-market, retorno dos dividendos, liquidez dos ativos, fluxo de caixa em relação ao preço, crescimento histórico das vendas, preço em relação às vendas e a variância de cada ativo.

Entre os testes empíricos do CAPM, admitindo o beta estático, que foram efetuados nesses trabalhos, , destacam-se Black, Jensen e Scholes (1972), que estudaram todas as ações transacionadas na New York Stock Exchange (NYSE) no período de 1931 a 1965, e verificaram alfas significantes estatisticamente, tendo relação com os betas. Eles sugeriram a existência de uma relação linear positiva entre os betas e o retorno (HAUGEN, 2001). Esses resultados são convergentes com Douglas (1969, apud SILVA et al. , 2009), e divergentes quando as contribuições de Black (1972) são excluídas.

Fama e MacBeth (1973) constituíram 20 carteiras com ativos negociados na NYSE, entre 1926 e 1929. Foram estimados os betas (estacionários) das carteiras com os retornos mensais do índice de mercado, de 1930 a 1934 . E, a fim de predizer os retornos mensais das carteiras no corte posterior entre 1935 e 1938, os betas das carteiras foram aplicados no corte temporal anterior. Eles aplicaram a média do valor de cada beta para encontrar sua significância. Com essa metodologia para estimação das regressões, eles chegaram às seguintes considerações: carteiras com betas acima da média posteriormente poderiam resultar em retornos acima da média; evidências foram encontradas da relação linear entre o beta e o retorno; não foi possível predizer o retorno futuro, lastreado no resíduo da variância dos ativos; e o retorno de carteiras compostas por ações negociadas no mercado seriam uma proxy da sua expectativa de retorno. Em vista disso, Haugen (2001) indicou que eles obtiveram resultados alinhados às premissas do modelo. Tambosi Filho, Costa Júnior e Rossetto (2006) citam que a variância residual não deve interferir no valor dos ativos ou do retorno exigido. Além disso, os estudos de Fama e French não indicaram que as ações com essa variância acima da média resultavam em retornos futuros acima dessa média. E, com seus resultados, o modelo solidificou-se diante dos pesquisadores.

No trabalho de Blume e Friend (1973), foram avaliadas todas as ações ordinárias listadas na NYSE, de 1950 a 1968, em função de seu risco não-diversificável, retornos mensais e betas 
estáticos, no período de 5 anos. Apesar de sugerirem a existência de relacionamento linear entre tais componentes do CAPM, nesse horizonte temporal, as taxas livres de risco, depois das regressões cross-sectional, mostraram-se estatisticamente distintas da taxa livre de risco real, o que é justificado sob o prisma de Black (1972). Frente a essa inconsistência do modelo, Blume e Friend indicaram como possíveis causas: i) as limitações em relação as short sales de ações; ii) a impossibilidade dos investidores fornecerem e contratarem crédito simultaneamente; e iii) as anomalias de mercado, que entre ativos e obrigações, geram tratamentos fiscais diferenciados. Além disso, por intermédio da estatística multivariada, foram estudadas algumas ineficiências que possibilitaram averiguar que outras variáveis, sobretudo o múltiplo de preço contábil/ preço de mercado (positiva relação com a rentabilidade) e size effect (negativa relação com a rentabilidade), pesquisados por Banz (1981) e Reinganum (1981), eram estatisticamente significantes para explicar a rentabilidade média, trazendo à tona hipóteses do relacionamento dos retornos, além de evidências robustas contra a efetividade do CAPM convencional (FAMA e FRENCH, 1992). Nesse contexto, constatou-se que os ativos com elevados índices P/L e bookto-value, book-to-market tiveram retornos maiores, de acordo com Basu (1977) e Lakonishok, Shleifer e Vishny (1994)

Por outro lado, Jagannathan e Wang (1996) encontraram fortes evidências a favor do CAPM básico, quando utilizaram como proxy do portfolio de mercado o índice CRSP, obtendo um poder explanatório de $30 \%$ da variação cross-section do retorno de 100 carteiras. Essa alteração na proxy corroborou as constatações de Fama e French (1992), ao verificaram que a proxy geralmente utilizada (ativos da NYSE e da American Stock Exchange - AMEX) não foi suficiente para uma análise satisfatória da performance do CAPM.

Em decorrência disso, e com o objetivo de melhorar a proxy, Jagannathan e Wang (1996) seguiram Mayers (1972) e incluíram em seu modelo o retorno do capital humano. Quando o capital humano foi, também, incluído na carteira de mercado, o modelo não-condicional implícito no CAPM condicional foi capaz de explicar mais de 50\% da variação cross-sectional do retorno médio. Além disso, os testes estatísticos não permitiram a rejeição do modelo.

Lucas (1978) e Breeden (1979), em seus artigos, assinalaram que as anomalias intertemporais do modelo seriam sanadas pelo relacionamento entre consumo e retorno. Hansen e Singleton (1983), em seus testes estatísticos, não aceitaram esse modelo no mercado americano, com a justificativa da impossibilidade de capturar de forma comum as variações das taxas de juros, dos retornos das ações e dos bonds.

Com o modelo 3-fatores, Fama e French(1993) visualizaram coeficientes estatisticamente distintos de zero, salientando as anomalias relacionadas à expectativa de retorno, já que o prêmio de risco não seria função apenas da covariância, mas, também, do preço dos ativos, isto é, o efeito tamanho. No mesmo sentido, Jagannathan e Wang (1996) indicaram que os retornos e os betas estão relacionados linear e positivamente, na presença do fator capital humano na carteira de mercado, e que os betas são simétricos ao ciclo dos negócios da firma.

Já Campbell (1993) desenvolveu o modelo multifatorial em que as variáveis explicativas do retorno requerido e o risco apresentaram variação no decorrer do período e seriam dependentes da futura taxa de consumo de riqueza.

Ferson e Harvey (1991) criaram um modelo de precificação com beta não-estacionário, 
acompanhando a oscilação das informações. Eles corroboraram que os betas não foram estatisticamente distintos de zero, o que conferiu satisfatório poder explanatório da variação cross-section dos retornos.

Para Silva et al. (2009), o CAPM nas versões condicionais seria adequado quando as variáveis macroeconômicas são inconstantes, porquanto as generalizações do modelo poderiam capturar, de forma intertemporal, as variações nos retornos das ações devido às novas informações, o que é conhecido como time-varying risk. Nessa perspectiva, as informações dos investidores do período $t-1$ seriam determinantes para o risco conjuntural. Segundo Hansen e Richard (1987), isso vem sendo evidenciado em várias pesquisas, tais como: Bollerslev, Engle e Wooldridge (1988), Schwert e Seguin (1989), Bodurtha e Mark (1991), Jagannathan e Wang (1996), Ferson e Harvey (1991).

Conforme Ribenboim (2004), citado por Silva et al. (2009), o CAPM básico é efetivo no mercado, em condições de equilíbrio, e suas generalizações apresentam melhor desempenho, especialmente nas economias com menor eficiência de mercado e liquidez dos ativos.

É importante mencionar que devem ser respeitados alguns pressupostos para o desenvolvimento de testes empíricos com o CAPM, quais sejam: i) o intercepto não pode ser significativamente diferente de zero; ii) o beta deve ser o único que explica a taxa de retorno do ativo com risco; iii) o trade-off risco-retorno deve ser linear; e iv) a carteira de mercado deve possuir maior risco do que o ativo livre de risco, sendo que, no longo prazo, as estimativas de retorno devem seguir essa trajetória. E, particularmente no Brasil, as proxies mais utilizadas para os componentes do CAPM são o Ibovespa (carteira de mercado) e o CDI ou a SELIC (ativo livre de risco).

A equação 1 corresponde à versão convencional do CAPM de Sharpe (1963 e 1964):

$$
r_{t}=\gamma_{0}+\gamma_{1} \boldsymbol{\beta}+\boldsymbol{\varepsilon}_{t}
$$

sendo,

$r_{t=} \ln ($ carteira de mercado $)-\ln \left(\right.$ carteira de mercado $\left._{t-1}\right)$;

$\gamma_{0}=$ coeficiente de intercepto;

$\gamma_{1=} r_{M t}-r_{F t}$

$r_{M t}=\ln \left(\right.$ carteira de mercado $\left._{t}\right)-\ln \left(\right.$ carteira de mercado $\left._{t-1}\right)$;

$r_{F t}=\ln ($ ativo livre de risco $)-\ln \left(\right.$ ativo livre de risco $\left._{t-1}\right)$;

$\boldsymbol{\beta}=$ coeficiente beta;

$\boldsymbol{\varepsilon}_{t}$ são os erros.

\subsection{Conditional CAPM: C-CAPM}

Em relação às versões variantes do CAPM, Merton (1973) desenvolveu o CAPM intertemporal (ICAPM), modelo que já procurava capturar as variações, ao longo do tempo e, 
para isso, considerava que a riqueza dos investidores era completamente consumida após um determinado período, porém, isso gerava inconsistências para sua avaliação. Já o ConditionalCAPM (C-CAPM) de Lewellen e Negel (2003), tem apresentado performance satisfatória e, portanto, tem sido bastante apreciado, pois considera as oscilações das variâncias e covariâncias no horizonte temporal (o que gera a quebra estrutural ou não-estacionariedade das séries), e o risco sistemático não é percebido como sendo estático.

No C-CAPM, para que as mudanças no ambiente macro e no comportamento da firma possam ser captadas com precisão, o prêmio de risco pode ser alterado de acordo com a variação condicional entre o retorno da ação e o do portfolio de mercado, e o prêmio de risco do portfolio de mercado (RIBENBOIM, 2004 apud SILVA et al. , 2009). Cochrane (1996) argumentou que $50 \%$ dos problemas de apreçamento via CAPM estático são causados pelo tamanho do portfolio, que Chen, Roll e Ross (1986), os resultados são reduzidos com a ampliação de variáveis macroeconômicas.

Na Austrália, Durack, Durand e Maller (2004) verificaram que essa variante explica, satisfatoriamente, a variação cross-sectional no mercado interno. Com a introdução de outras variáveis, pode-se ter um desempenho ainda melhor. No estudo de Tambosi, Costa Jr. e Rosseto (2006), com a aplicação das variáveis size e capital humano, constatou-se o elevado poder explicativo do C-CAPM nos mercados brasileiro e norte-americano.

Na versão de Bawa e Lindenberg (1977) as assimetrias são capturadas à luz do Lower Partial Moment, pois os retornos dos ativos relacionados à seleção do investimento têm distribuições assimétricas. Complementando, Estrada (2000) indicou o downside risk para auxiliar na explicação dos retornos em economias emergentes, e, por meio de testes relacionados a uma amostra de 27 dessas economias, verificou que o CAPM, que considera downside risk, possui maior poder explicativo do que a versão convencional, com argumentos consistentes para concluir sobre a supremacia da média-semivariância, sobremaneira, nessa amostra de emergentes. Consoante a isso, Lópes et al. (1999 apud SILVA, MELO e PINTO, 2009) comprovou que a versão estática subavaliava os retornos no México.

A equação 2 corresponde a uma das versões condicionais do CAPM (C-CAPM), sendo a de Lewellen e Negel (2003) uma das mais utilizadas:

$$
r_{t}=\alpha+\beta_{1} \gamma_{t}+\beta_{2} \gamma_{t-1}+\varepsilon_{t}
$$

sendo,

$r_{t=} \ln ($ carteira de mercado $)-\ln \left({\left.\text { carteira de } \text { mercado }_{t-1}\right) ;}\right.$;

$\boldsymbol{\alpha}=$ coeficiente de intercepto;

$\boldsymbol{\beta}_{1}=$ coeficiente beta parcial a ser estimado no tempo t;

$\boldsymbol{\beta}_{2}=$ coeficiente beta parcial a ser estimado no tempo t-1;

$\gamma_{\mathrm{t}=} r_{M t}-r_{F t}$

$r_{M t}=\ln \left(\right.$ carteira de mercado $\left._{t}\right)-\ln \left(\right.$ carteira de mercado $\left._{t-1}\right)$;

$r_{F t}=\ln ($ ativo livre de risco $)-\ln \left(\right.$ ativo livre de risco $\left.{ }_{t-1}\right)$;

$\boldsymbol{\varepsilon}_{t}$ são os erros. 


\subsection{Downside CAPM: D-CAPM}

A partir de estudos anteriores, Estrada (2002) desenvolveu o Downside-CAPM (D-CAPM), que constitui uma generalização do modelo básico, utilizando a semivariância como métrica de dispersão dos retornos, e tendo como pressuposto o estudo da perda sistêmica.

Em se tratando do mercado internacional, destacam-se os artigos de Harvey e Siddique (1999), que comprovaram um desempenho mais elevado em mercados americanos e emergentes, por intermédio de testes estatísticos do D-CAPM.

Mais tarde, Black (1972) derivou uma versão do modelo que o beta era definido em termos de retornos do portfolio de mínima variância de todos os portfolios (zero-beta return).

Barbosa e Motta (2004) testaram o D-CAPM no país, comparando o custo de capital por meio do CAPM e D-CAPM, nas economias do Brasil, Argentina, México, Chile, e perceberam que a adoção de alguns dos modelos provoca impacto no processo decisório da empresa ou do acionista, já que a variante proporcionou melhor poder explicativo dos retornos.

Por fim, o trabalho de Silva (2007) foi convergente com este último, tendo analisado a versão convencional e essas duas variantes, por meio do estudo de 100 ativos com acentuado volume de transações na BOVESPA, selecionados em 14 portfolios, de 1995 a 2005.

A equação 3, de Estrada (2000), corresponde a uma das versões downside do CAPM (D-CAPM) mais aplicadas nas pesquisas:

$$
r_{t}=\gamma_{0}+\gamma_{1} d \beta_{i}+\boldsymbol{\varepsilon}_{t}
$$

sendo,

$r_{t=} \ln ($ carteira de mercado $)-\ln \left(\right.$ carteira de mercado $\left._{t-1}\right)$;

$\gamma_{0}=$ coeficiente de intercepto;

$\gamma_{1=} r_{M t}-r_{F t}$

$r_{M t}=\ln \left(\right.$ carteira de mercado $\left._{t}\right)-\ln \left(\right.$ carteira de mercado $\left._{t-1}\right)$;

$r_{F t}=\ln ($ ativo livre de risco $)-\ln \left(\right.$ ativo livre de risco $\left._{t-1}\right)$;

$d \beta_{i}=$ downside beta, $d \beta_{i}=\mathrm{S}_{\mathrm{im}} / \mathrm{S}_{\mathrm{m}}^{2} ;$

$\mathrm{S}_{\mathrm{im}}=\mathrm{E}\left\{\operatorname{Min}\left[\left(r_{i}-\boldsymbol{\mu}_{\mathrm{i}}\right), 0\right] \operatorname{Min}\left[\left(r_{M t}-\boldsymbol{\mu}_{M t}\right), 0\right]\right\}$ é a semicovariância do mercado com o ativo;

$\mathrm{S}_{\mathrm{m}=}^{2} \mathrm{E}\left\{\operatorname{Min}\left[\left(r_{M t}-\boldsymbol{\mu}_{M t}\right), 0\right]^{2}\right\}$ é a semivariância;

$\boldsymbol{\varepsilon}_{t}$ são os erros.

Outras versões anteriores são a intertemporal de Merton (1973) e a Consumo de Lucas (1978) e Breeden (1979), entre outras. 


\subsection{Trabalhos sobre o Modelo CAPM no Brasil}

Vários pesquisadores têm desenvolvido trabalhos sobre o CAPM e variantes no mercado brasileiro, para testar sua adequação e poder explicativo no que se refere a ativos individuais ou portfolios. Nos Quadros 1, 2 e 3 são apresentados alguns deles, publicados nos últimos anos.

\begin{tabular}{|c|c|c|}
\hline Autor & Objetivo & Conclusão \\
\hline $\begin{array}{l}\text { Rochman e Eid Jr. } \\
\qquad(2006)\end{array}$ & $\begin{array}{l}\text { Investigar se é melhor investir em fundos } \\
\text { ativos ou passivos. }\end{array}$ & $\begin{array}{l}\text { Confirmou-se a efetividade do CAPM na } \\
\text { estimativa do risco de fundos. }\end{array}$ \\
\hline $\begin{array}{l}\text { Silva e Munhoz } \\
\qquad(2006)\end{array}$ & $\begin{array}{l}\text { Determinar se seria possível utilizar o } \\
\text { lucro líquido de empresas fechadas e sua } \\
\text { dispersão, uma medida contábil, como } \\
\text { uma aproximação do beta. }\end{array}$ & $\begin{array}{l}\text { O modelo foi considerado efetivo para } \\
\text { mensuração do risco. }\end{array}$ \\
\hline $\begin{array}{c}\text { Tambosi Filho, Costa Jr. } \\
\text { e Rossetto } \\
\text { (2006) }\end{array}$ & $\begin{array}{l}\text { Apresentar as vantagens dos modelos } \\
\text { condicionais em relação ao modelo } \\
\text { estático. }\end{array}$ & $\begin{array}{l}\text { O C-CAPM é mais eficiente nas } \\
\text { previsões que o CAPM. }\end{array}$ \\
\hline $\begin{array}{l}\text { Galdi e Securato } \\
\qquad(2007)\end{array}$ & $\begin{array}{l}\text { Analisar a relação entre o risco } \\
\text { idiossincrático e o retorno de uma carteira } \\
\text { diversificada no Brasil. }\end{array}$ & $\begin{array}{l}\text { Rejeitou-se o desempenho preditivo do } \\
\text { CAPM. }\end{array}$ \\
\hline $\begin{array}{l}\text { Lins, Silva e Marques } \\
\qquad(2007)\end{array}$ & $\begin{array}{l}\text { Construir carteiras de ações com } \\
\text { características homogêneas de risco } \\
\text { versus retorno. }\end{array}$ & $\begin{array}{l}\text { O CAPM apresentou bom desempenho } \\
\text { para calcular o risco. }\end{array}$ \\
\hline $\begin{array}{l}\text { Rabelo et al. } \\
\text { (2007) }\end{array}$ & 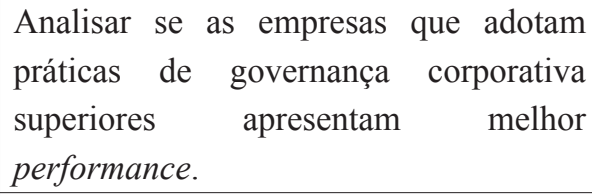 & $\begin{array}{l}\text { A ineficiência do modelo foi justificada } \\
\text { pelas características da amostra } \\
\text { pesquisada. }\end{array}$ \\
\hline $\begin{array}{l}\text { Rogers e Securato } \\
\qquad(2008)\end{array}$ & $\begin{array}{l}\text { Testar e comparar três modelos } \\
\text { alternativos para predição de retornos } \\
\text { esperados no mercado de capitais } \\
\text { brasileiro. }\end{array}$ & $\begin{array}{l}\text { Rejeitou-se o CAPM para predizer os } \\
\text { retornos. }\end{array}$ \\
\hline $\begin{array}{l}\text { Raboni et al. } \\
\qquad(2008)\end{array}$ & $\begin{array}{l}\text { Testar a estratégia de investir em ações } \\
\text { que apresentaram crescimento nos } \\
\text { últimos anos. }\end{array}$ & $\begin{array}{l}\text { O CAPM apresentou melhor poder } \\
\text { explicativo quando acrescentada outra } \\
\text { variável. }\end{array}$ \\
\hline $\begin{array}{c}\text { Castro Silva, Melo e } \\
\text { Pinto } \\
(2009)\end{array}$ & $\begin{array}{l}\text { Investigar qual dos modelos (CAPM, } \\
\text { D-CAPM ou C-CAPM) seria mais estável } \\
\text { e melhor se ajustariaàs estimativas do } \\
\text { retorno de índices de ações negociadas na } \\
\text { Bovespa. }\end{array}$ & $\begin{array}{l}\text { Sugeriu-se que o C-CAPM foi } \\
\text { ligeiramente mais estável. E a presença } \\
\text { de mudanças estruturais nas séries } \\
\text { também apontou que o beta não é o } \\
\text { único fator que explicaria o risco. }\end{array}$ \\
\hline $\begin{array}{l}\text { Castro Silva et al. } \\
\qquad \text { (2009) }\end{array}$ & $\begin{array}{l}\text { Testar e comparar o CAPM na versão } \\
\text { estática e o CAPM na versão condicional. }\end{array}$ & $\begin{array}{l}\text { Evidenciou-se maior eficiência do } \\
\text { C-CAPM, por apresentar menores } \\
\text { critérios de informações de Akaike e } \\
\text { Schwarz, sem a presença de quebra } \\
\text { estrutural. }\end{array}$ \\
\hline
\end{tabular}

Quadro 1: Trabalhos sobre o modelo CAPM - Testes em portfolios de ativos

Fonte: Elaborado pelos autores.

Nota-se que a maioria (cerca de $70 \%$ ) dos artigos que realizaram testes do CAPM e 
variantes, em portfolio de ativos, consideraram-no efetivo na precificação. Houve três pesquisas que compararam o desempenho do CAPM e do C-CAPM e, em todas elas, esta variante mostrouse mais eficiente, sendo esta uma informação relevante para os usuários da ferramenta. Uma das pesquisas creditou a ineficiência verificada do modelo à amostra utilizada, e não às anomalias na teoria.

\begin{tabular}{|c|c|c|}
\hline Autor & Objetivo & Conclusão \\
\hline $\begin{array}{l}\text { Ceretta, Catarina e } \\
\text { Muller (2007) }\end{array}$ & $\begin{array}{l}\text { Analisar o efeito da inclusão das variáveis assimetria } \\
\text { sistemática e curtose sistemática no CAPM. }\end{array}$ & $\begin{array}{lr}\text { Corroborou-se } & \text { o } \\
\text { desempenho explicativo } \\
\text { do CAPM. }\end{array}$ \\
\hline $\begin{array}{l}\text { Motta, Fortunato e } \\
\quad \text { Russo (2007) }\end{array}$ & $\begin{array}{l}\text { Testar empiricamente a proposta de Estrada (2000) para } \\
\text { as empresas que compõem o Ibovespa, avaliando se, para } \\
\text { os mercados emergentes, existem medidas de risco mais } \\
\text { adequadas do que o beta. }\end{array}$ & $\begin{array}{l}\text { O D-CAPM foi } \\
\text { considerado pouco } \\
\text { adequado para estimar o } \\
\text { custo do capital próprio no } \\
\text { Brasil. }\end{array}$ \\
\hline $\begin{array}{l}\text { Casotti e Motta } \\
(2008)\end{array}$ & $\begin{array}{l}\text { Verificar se as ações das empresas estavam subavaliadas } \\
\text { ou super-avaliadas no momento das IPOs. }\end{array}$ & $\begin{array}{l}\text { O poder de predição do } \\
\text { CAPM foi refutado. }\end{array}$ \\
\hline $\begin{array}{c}\text { Castro Jr. e } \\
\text { Yoshinaga (2008) }\end{array}$ & $\begin{array}{l}\text { Analisar modelos de precificação de ativos incluindo } \\
\text { novos fatores potencialmente relevantes na explicação } \\
\text { do comportamento das taxas de retorno. }\end{array}$ & $\begin{array}{l}\text { Corroborou-se o } \\
\text { desempenho preditivo do } \\
\text { CAPM. }\end{array}$ \\
\hline Salmasi (2008) & $\begin{array}{l}\text { Analisar a relação entre governança corporativa e o custo } \\
\text { de capital próprio em empresas brasileiras de capital } \\
\text { aberto. }\end{array}$ & $\begin{array}{l}\text { Confirmou-se o } \\
\text { desempenho estimativo do } \\
\text { CAPM. }\end{array}$ \\
\hline $\begin{array}{l}\text { Mazer e Nakao } \\
\qquad(2008)\end{array}$ & $\begin{array}{l}\text { Verificar a existência de relação entre o nível de } \\
\text { transparência e o custo de capital próprio das empresas } \\
\text { integrantes do Ibovespa. }\end{array}$ & $\begin{array}{l}\text { Corroborou-se } \\
\text { efetividade do CAPM. }\end{array}$ \\
\hline
\end{tabular}

Quadro 2: Trabalhos sobre o modelo CAPM - Testes em ativos individuais

Fonte: Elaborado pelos autores.

Os estudos que desenvolveram testes em ativos individuais utilizaram, na maior parte, o modelo CAPM convencional. Em mais de $71 \%$ deles, a eficiência do modelo foi confirmada. Somente um dos trabalhos testou uma versão alternativa, o D-CAPM, a qual foi refutada. Logo, o restante preferiu estudar a versão básica. Salienta-se que, em algumas das pesquisas, foram incluídas no modelo outras variáveis para verificar a ampliação de sua eficiência, o que foi constatado.

\begin{tabular}{|c|l|l|}
\hline Autor (es) & \multicolumn{1}{|c|}{ Objetivo } & \multicolumn{1}{|c|}{ Conclusão } \\
\hline $\begin{array}{c}\text { Garrán e } \\
\text { Martelanc (2007) }\end{array}$ & $\begin{array}{l}\text { Descrever as principais metodologias utilizadas por } \\
\text { avaliadores de ativos do Brasil ao estimar o custo de } \\
\text { capital próprio na composição da taxa de desconto dos } \\
\text { FC para o método do FCD. }\end{array}$ & $\begin{array}{l}\text { O CAPM é o modelo mais } \\
\text { utilizado no Brasil quando o } \\
\text { contexto permite sua aplicação. }\end{array}$ \\
\hline $\begin{array}{c}\text { Saito e Bueno } \\
(2007)\end{array}$ & $\begin{array}{l}\text { Discorrer sobre alguns importantes fundamentos } \\
\text { teóricos e empíricos acerca do CAPM. }\end{array}$ & $\begin{array}{l}\text { Sugeriu-se haver novos } \\
\text { questionamentos sobre a } \\
\text { efetividade do CAPM. }\end{array}$ \\
\hline $\begin{array}{c}\text { Piloto, Senra e } \\
\text { Moreno (2008) }\end{array}$ & $\begin{array}{l}\text { Propor uma nova formula para o cálculo do WACC } \\
\text { e comparar os valores encontrados pelas formulas } \\
\text { tradicional e proposta, para valor justo da ação da } \\
\text { Aracruz Celulose. }\end{array}$ & $\begin{array}{l}\text { Considerou-se a efetividade do } \\
\text { CAPM para estimar o Ke. }\end{array}$ \\
\hline
\end{tabular}

Quadro 3: Trabalhos sobre o modelo CAPM - Não realizaram testes em ativos

Fonte: Elaborado pelos autores. 
Outros tipos de pesquisas, diferentes das usuais que realizaram testes empíricos, elaboraram trabalhos qualitativos e discussões de cunho teórico, revelando que o CAPM é o modelo de precificação de ativos mais utilizado no Brasil. Mas, existem questionamentos em torno de sua efetividade para gerar um poder explicativo/preditivo satisfatório, conforme constatado nos trabalhos empíricos (quadros 1 e 2), o que se deve a questões metodológicas (dados inadequados para testar o modelo) ou à insuficiência de variáveis - redutoras da precisão do CAPM.

Verifica-se que as pesquisas dos últimos anos no Brasil, procurando estudar o CAPM e suas variantes, têm ocorrido por intermédio de diferentes abordagens, gerando, assim, resultados que têm contribuído para conhecer o seu comportamento nesse mercado.

\section{METODOLOGIA}

Esta pesquisa, com abordagem teórico-descritiva, busca descrever o comportamento, características ou funções dos fenômenos (COLLIS e HUSSEY, 2005), através de um levantamento dos artigos acadêmicos abordando o CAPM e variantes no país, entre 1997 e 2008, apresentados nos EnANPADs e em periódicos nacionais, para conhecer suas principais características e constatações. A seleção desse período é justificada pelo intuito de estudar as publicações relativas a uma década, além daquelas disponibilizadas nos anais eletrônicos da ANPAD, a partir de 1997.

Trata-se de um trabalho qualitativo (COLLIS e HUSSEY, 2005), o qual procura apontar aspectos relacionados às características de pesquisas anteriores que sejam importantes do ponto de vista conceitual e prático do modelo, e que tenham sido aplicadas no contexto econômico do país. Assim, possui uma natureza teórica, ainda que examine trabalhos empíricos.

A unidade de observação foi cada artigo da amostra, o qual teve o seu conteúdo verificado para a identificação das principais aplicações do modelo, da metodologia utilizada nos testes empíricos e das principais constatações.

Foram investigados os anais de 1997 a 2008 dos EnANPADs- um dos mais importantes congressos de administração e contabilidade do país, que recepciona boa parte dos artigos produzidos nestas áreas - portanto, um período de 12 anos, além de seis periódicos brasileiros na área de administração e economia, classificados no Qualis-CAPES como de elevado impacto, a saber: Revista Brasileira de Finanças (RBFIN), Revista de Administração de Empresas (RAE), Revista de Administração da Universidade de São Paulo (RAUSP), Revista de Administração Contemporânea (RAC), Revista de Administração Contemporânea (RAC-e), Revista Brasileira de Economia (RBE), meios nos quais se procedeu uma varredura em busca de artigos, que compuseram a amostra de 43 pesquisas (vide TAB. 1). Cabe ressaltar que nos dois últimos periódicos, não foram encontrados artigos sobre o tema no período. Nos anos de 1999 e 2001, também não foram identificadas publicações sobre o modelo. Um artigo foi excluído da amostra por ter sido considerado idêntico a outro já contabilizado (em periódico), pois, além de não reforçar os resultados obtidos, seria redundante.

Os artigos que estudaram apenas a métrica beta do CAPM também, foram incluídos na amostra, por traduzir importantes prerrogativas do modelo, e por ser estudado enquanto medida 
que reflete o risco não sistemático das empresas.

A coleta de dados ocorreu por meio eletrônico ou através das versões impressas desses periódicos, e nos anais eletrônicos dos EnANPADs - divisões de contabilidade e finanças. Foram selecionados todos os artigos que realizaram estudos sobre ou com o CAPM e variantes, os quais foram identificados com base nos termos: CAPM, C-CAPM, D-CAPM, Capital Asset Pricing Model, Modelo de Precificação de Ativos Financeiros, Downside-CAPM e ConditionalCAPM. Esses termos foram procurados, primeiramente, no título dos trabalhos; depois, no resumo; e, por último, nas palavras-chave. Após este levantamento, a base de dados englobou todos os 43 artigos encontrados, que foram, posteriormente, examinados. O fato de o trabalho abordar o CAPM e variantes, o incluía na amostra, logo, só foi excluído aquele em duplicidade (já apontado acima).

Especificamente, foram averiguadas as seguintes variáveis em cada artigo:

1) metodologia:

i) completude dos dados informados na metodologia;

ii) tipos de análise;

iii) métodos utilizados;

iv) testes realizados;

v) principais bases de dados consultadas;

vi) proxies da carteira de mercado;

vii) proxies do ativo livre de risco;

viii) tipos de ações;

ix) períodos estudados (anos);

$\mathrm{x})$ testes em ativos individuais ou em portfolios;

2) nos resultados e conclusões:

xi) sobre as convergências ou divergências aos modelos;

Com o intuito de constatar similaridades, foram ainda cruzados os dados dos artigos que convergiram e que divergiram sobre os modelos e as variáveis acima: i; ii; v; vii; ix.

Destaca-se que a classificação dessas informações é subjetiva, face à percepção ou à compreensão dos autores sobre o tema. Os dados de cada artigo foram analisados pelos autores, em sequência, visando evitar ambiguidades nas interpretações dos resultados, o que poderia prejudicar as análises. Deste modo, eventuais dúvidas foram solucionadas pelo consenso entre os autores, refletindo a interpretação deles sobre as informações levantadas.

Os dados coletados foram tabulados e submetidos às análises estatísticas descritivas 
(MOORE, 2005), utilizando-se, ainda, a tabela dinâmica/cruzada (cross table) por intermédio do software Microsoft Excel ${ }^{\circledR}$ 2007. Os resultados são apresentados e discutidos na próxima seção.

Tabela 1: Artigos encontrados no período de 1997 a 2008

\begin{tabular}{l|c|c|c|c|c|c|c|c|c|c|c}
\hline & $\mathbf{1 9 9 7}$ & $\mathbf{1 9 9 8}$ & $\mathbf{2 0 0 0}$ & $\mathbf{2 0 0 2}$ & $\mathbf{2 0 0 3}$ & $\mathbf{2 0 0 4}$ & $\mathbf{2 0 0 5}$ & $\mathbf{2 0 0 6}$ & $\mathbf{2 0 0 7}$ & $\mathbf{2 0 0 8}$ & TOTAL \\
\hline EnANPAD & 4 & 5 & 1 & 4 & 4 & 2 & 3 & 2 & 5 & 6 & $\mathbf{3 6}$ \\
\hline RBFIN & & & & & & 1 & & & 1 & 1 & $\mathbf{3}$ \\
\hline ERA & & & & & & & & & 1 & & $\mathbf{1}$ \\
\hline RAUSP & & & & 1 & & & & & & & $\mathbf{1}$ \\
\hline RAC & & & & & & 1 & & 1 & & & $\mathbf{2}$ \\
\hline \multicolumn{1}{c}{ Total } & $\mathbf{4}$ & $\mathbf{5}$ & $\mathbf{1}$ & $\mathbf{5}$ & $\mathbf{4}$ & $\mathbf{5}$ & $\mathbf{3}$ & $\mathbf{3}$ & $\mathbf{7}$ & $\mathbf{7}$ & $\mathbf{4 3}$ \\
\hline
\end{tabular}

\section{APRESENTAÇÃO E DISCUSSÃO DOS RESULTADOS}

Nesta seção, apresentamos uma síntese dos dados compilados nos 43 artigos publicados no período de 12 anos (TAB. 1), e nos meios de comunicação acadêmica pesquisados.

Pode-se constatar que, dessa amostra selecionada, apenas Neves e Amaral (2002), Soares, Rostagno e Soares (2002), Zimmerman e Lemme (2002), Montavani, Bertucci e Bressan (2003), Araújo, Bressan e Bertucci (2004), Rostagno, Kloeckner e Becker (2004), Filho, Costa Jr. e Rosseto (2006), Motta, Fortunato e Russo (2007), Rogers e Securato (2007), Costa Júnior e Yoshinaga (2008), Raboni et al. (2008) e Salmasi (2008), realizaram estudos comparativos sobre o desempenho de modelos de precificação de ativos. Isso equivale a quase $28 \%$ da amostra (quase 1/3). Portanto, a maior parte dos autores preocupou-se em estudar, especificamente, as características do CAPM, ou testar seu desempenho/poder explicativo, bem como verificar a existência de anomalias. Em suma, o acréscimo de variáveis explicativas sinalizou o aumento da eficiência no apreçamento de ativos, tornando, contudo, a operacionalização dos modelos mais complexa, o que, para alguns usuários da ferramenta, onera a relação custo $\mathrm{x}$ benefício de sua utilização. Logo, muitos deles preterem sua aplicação, preferindo a versão básica do CAPM, como revelado no survey de Garrán e Martelanc (2007).

Tabela 2: Convergências x Divergências ao CAPM

\begin{tabular}{c|c|c|c}
\hline & Quantidade & $\mathbf{\%}$ & \% acumulado \\
\hline Artigos convergentes & 25 & 58,14 & 58,14 \\
\hline Críticas ao CAPM & 18 & 41,86 & 100,00 \\
\hline Total & $\mathbf{4 3}$ & $\mathbf{1 0 0 , 0 0}$ & \\
\hline
\end{tabular}

Fonte: Elaborada pelos autores.

Mesmo diante de muitas críticas sobre o desempenho, i.e., o poder preditivo do CAPM básico, em 25 artigos, confirmou-se sua efetividade na precificação de ativos. Isso corresponde a pouco mais de $58 \%$ da amostra. O restante dos trabalhos não confirmou a efetividade do CAPM, seja na versão básica, nas versões avançadas ou em comparação com outros modelos de apreçamento, sendo que quase $42 \%$ rejeitaram sua capacidade de predizer o retorno do acionista. 
Tabela 3: Completude dos dados informados na metodologia

\begin{tabular}{|c|c|c|c|}
\hline Forma de observação & Quantidade & $\%$ & $\%$ acumulado \\
\hline Dados informados completamente & 27 & 62,79 & 62,79 \\
\hline $\begin{array}{l}\text { Não informaram proxies do ativo livre de risco, da carteira } \\
\text { de mercado e banco de dados utilizados }\end{array}$ & 3 & 6,98 & 69,77 \\
\hline Dados informados incompletos & 13 & 30,23 & 100,0 \\
\hline Total & 43 & 100,0 & \\
\hline
\end{tabular}

Fonte: Elaborada pelos autores.

Quanto aos tipos de dados, em aproximadamente 7\% dos artigos (3) não estavam explícitos os dados sobre a proxy do ativo livre de risco utilizada, da carteira de mercado, a origem ou base de dados em que foram extraídos, além de outras informações relacionadas à operacionalização dos testes empíricos. E, em pouco mais de $30 \%$ dos artigos (13), os dados estavam incompletos.

O maior problema relacionado à descrição incompleta dos dados está na impossibilidade de o trabalho ser reproduzido por outros autores e, ainda, na dificuldade de compreensão da pesquisa por parte do leitor. Das pesquisas que apontaram os dados incompletos, $92 \%$ são oriundas do EnANPAD, e o restante - apenas um trabalho - foi publicado em periódico. Partindo-se do pressuposto de que os trabalhos publicados em congresso, muitas vezes, estão em fase de confecção, isso, até certo ponto, pode ser justificado.

Tabela 4: Tipos de análise

\begin{tabular}{c|c|c|c}
\hline & Quantidade & $\mathbf{\%}$ & $\mathbf{\%}$ acumulado \\
\hline Cross-section & 37 & 86,05 & 86,05 \\
\hline Panel Data & 2 & 4,65 & 90,70 \\
\hline Cross-section e Panel Data & 1 & 2,33 & 93,02 \\
\hline Questionário & 2 & 4,65 & 97,67 \\
\hline Ensaio-teórico & 1 & 2,33 & 100,0 \\
\hline Total & $\mathbf{4 3}$ & $\mathbf{1 0 0 , 0}$ & \\
\hline
\end{tabular}

Fonte: Elaborada pelos autores.

Em relação ao tipo de análise, Garrán e Martelanc (2007) fizeram um trabalho qualitativo, aplicando questionário, e Mazer e Nakao (2008) constituíram uma pesquisa qualitativa e quantitativa, utilizando questionário e regressão linear simples. Já Motta, Fortunato e Russo (2007), realizaram uma análise com dados em Cross-section e Panel Data. Saito e Bueno (2007) desenvolveram um ensaio-teórico. Galdi e Securato (2008), Castro Jr. e Yoshinaga (2008) e Raboni et al. (2008), procederam à uma análise em Panel Data. Assim, verifica-se que pouco mais de $86 \%$ dos autores preferiram realizar análises Cross-section dos dados. E, juntos, os estudos Cross-section e Panel Data representaram expressivos 93\% da amostra.

De certa maneira, já era esperada uma maior concentração de artigos realizando 
essas análises, uma vez que, para testar empiricamente os modelos de precificação de ativos, utilizam-se regressões e, para tanto, os dados devem ser trabalhados por meio dessas duas alternativas. Menciona-se que, em geral, os autores não informaram o período das análises (mensal, trimestral, semestral, etc.). Para Bruni (1998), as análises de períodos menores podem ampliar a eficiência das regressões.

O CAPM também foi utilizado para estudar os fundos de investimento, destacando-se os artigos de Mattos et al. (1997), Ceretta e Costa Jr. (1998), Amaral et al. (2004) e Rochman e Eid Jr. (2006), representando quase $10 \%$ da amostra.

Tabela 5: Métodos utilizados

\begin{tabular}{c|c|c|c}
\hline Método utilizado & Quantidade & $\mathbf{\%}$ & $\begin{array}{c}\mathbf{\%} \\
\text { acumulado }\end{array}$ \\
\hline Regressão linear simples & 18 & 41,86 & 41,86 \\
\hline Regressão linear múltipla & 11 & 25,58 & 67,44 \\
\hline Regressões lineares simples e múltipla & 6 & 13,95 & 81,40 \\
\hline Outros métodos quantitativos & 6 & 13,95 & 95,35 \\
\hline Métodos qualitativos & 2 & 4,65 & 100,0 \\
\hline Total & $\mathbf{4 3}$ & $\mathbf{1 0 0 , 0}$ & \\
\hline
\end{tabular}

Fonte: Elaborada pelos autores.

No que se refere aos métodos utilizados para estudar o CAPM e variantes, em 18 estudos, i.e., quase $42 \%$ da amostra, os autores aplicaram a regressão linear simples, utilizando, em maior parte, a versão convencional do modelo. Em função da modelagem da equação do CAPM, tal método é bastante propício para seu teste empírico. Somente a regressão linear múltipla foi aplicada em 11 trabalhos (quase 26\%), pois, os autores trabalharam com modelos que utilizaram mais de um fator na avaliação do desempenho dos mesmos, ou, propriamente, adicionaram fatores à modelagem do modelo, para averiguar se os mesmos ampliariam sua eficiência. Já em 6 dos artigos (quase 14\%), os autores utilizaram tanto a regressão linear simples como a múltipla, segundo a conveniência para testar os modelos.

Tabela 6: Testes utilizados na análise univariada e multivariada para o modelo CAPM

\begin{tabular}{l|c|c|c}
\hline \multicolumn{1}{c|}{ Teste } & Quantidade & $\%$ & $\%$ acumulado \\
\hline t de Student/Studentized Range & 9 & 19,15 & 19,15 \\
\hline Durbin-Watson & 4 & 8,51 & 27,66 \\
\hline Jarque-bera & 3 & 6,38 & 34,04 \\
\hline VIF ou FIV & 3 & 6,38 & 40,43 \\
\hline White & 3 & 6,38 & 46,81 \\
\hline Hausman & 3 & 6,38 & 53,19 \\
\hline Eigenvalue & 2 & 4,26 & 57,45 \\
\hline Wald & 2 & 4,26 & 61,70 \\
\hline Kolmogorov-Smirnov $(K-S)$ & 2 & 4,26 & 65,96 \\
\hline Out of sample & 2 & 4,26 & 70,21 \\
\hline Chow & 2 & 4,26 & 74,47 \\
\hline Outros & 12 & 25,53 & 100,0 \\
\hline
\end{tabular}

Fonte: Elaborada pelos autores. 
Dos 24 artigos que aplicaram o método de regressão linear simples, 13 deles $(54,17 \%)$ indicaram a utilização de testes sobre as adequações de dados. Já em 11 artigos (45,83\%), a utilização de testes não foi identificada, quantia considerada elevada. Como essas pesquisas não apontam a execução de testes, e quais deles, isso pode tornar questionável suas conclusões, já que algum pressuposto do modelo pode ter sido violado, o que invalidaria/ os resultados e, consequentemente, as conclusões.

Já dentre os 17 artigos que aplicaram o método de regressão linear múltipla, 16 deles $(94,12 \%)$ indicaram a utilização de testes sobre as adequações dos dados. Apenas em 1 dos artigos $(5,88 \%)$ não se visualizou a aplicação de testes. Portanto, com este método, os autores revelaram maior preocupação em descrever os testes efetuados.

De uma forma geral, os testes mais aplicados foram o Studentized Range - para avaliar se os parâmetros estimados são significativos estatisticamente - e, o teste Durbin-Watson - que verifica a existência de heterocedasticidade entre os resíduos da regressão.

Cabe destacar a necessidade de que os testes efetuados sejam descritos na metodologia do trabalho, já que só assim o leitor poderá ter maior clareza de como os dados foram analisados, e, consequentemente, ter maior confiabilidade a respeito dos resultados gerados, os quais podem influenciar pesquisas futuras, além de permitirem o estabelecimento de comparações com trabalhos anteriores, principalmente testando de modo empírico a validade da teoria do CAPM, corroborando-a ou contestando-a, indicando anomalias, e fomentando novas pesquisas para que os mesmos sejam aperfeiçoados e apresentem desempenho superior para os seus usuários no mercado.

Tabela 7: Principais bases de dados consultadas

\begin{tabular}{c|c|c|c}
\hline Base de dados & Quantidade $^{\mathbf{a}}$ & $\mathbf{\%}$ & \% acumulado \\
\hline Economática & 26 & 59,09 & 59,09 \\
\hline BACEN & 4 & 9,09 & 68,18 \\
\hline CVM & 3 & 6,82 & 75,0 \\
\hline BOVESPA & 3 & 6,82 & 100,0 \\
\hline Outras & 8 & 18,18 & \\
\hline Total & $\mathbf{4 4}$ & $\mathbf{1 0 0 , 0}$ & \\
\hline
\end{tabular}

${ }^{a}$ Em alguns artigos consultou-se mais de uma base de dados.

Fonte:Elaborada pelos autores.

O principal banco de dados utilizado foi a Economática, em $50 \%$ das pesquisas. Outras bases menos consultadas foram: BOVESPA, CVM, FGV, Bloomberg, Lafis, DAIEA, ANBID, BACEN, Infomoney, Sabe Invest, Dow Jones e Nasdaq. Por ser considerada a fonte mais completa ao alcance dos pesquisadores, no Brasil, essa superioridade da Enonomática já era esperada, ainda que haja questionamentos sobre sua completude. E, em quase $10 \%$ dos artigos a base utilizada não foi informada. Já em aproximadamente $6 \%$, pelo caráter qualitativo, essas bases não foram utilizadas. 
Tabela 8: Proxies da carteira de mercado

\begin{tabular}{c|c|c|c}
\hline Proxy utilizada & Quantidade $^{\mathbf{a}}$ & $\mathbf{\%}$ & \% acumulado $^{*}$ \\
\hline Ibovespa & 21 & 60,0 & 60,0 \\
\hline FGV-100 & 3 & 8,57 & 68,57 \\
\hline IBRX & 2 & 5,71 & 74,29 \\
\hline Criada por autores & 3 & 8,57 & 82,86 \\
\hline Outras & 6 & 17,14 & 100,0 \\
\hline Total & $\mathbf{3 5}$ & $\mathbf{1 0 0 , 0}$ & \\
\hline
\end{tabular}

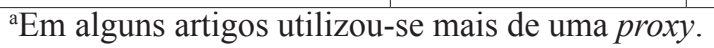

Fonte: Elaborada pelos autores.

Como proxy da carteira de mercado, venceu o Ibovespa, sendo referência em $60 \%$ dos casos em que foi necessário (cerca de 49\% dos artigos). O IBX, IGC, FGV-100, Global 40, S\&P500, S\&P/IFCG, MERVAL (Argentina), IPSA (Chile), IPC (México) também foram utilizados. Alguns autores (5\%) preferiram criar um índice que fosse mais ajustado ou conveniente ao caráter de suas pesquisas, ou aos pressupostos teóricos. Como é usual nos trabalhos em finanças no país, confirmou-se que o Ibovespa foi o portfolio de mercado mais aplicado.

Tabela 9: Proxies do ativo livre de risco

\begin{tabular}{c|c|c|c}
\hline Proxy & Quantidade & $\mathbf{\%}$ & \% acumulado \\
\hline CDI & 12 & 27,91 & 27,91 \\
\hline SELIC & 8 & 18,60 & 46,51 \\
\hline Poupança & 4 & 9,30 & 55,81 \\
\hline Outros & 6 & 13,95 & 69,77 \\
\hline Não informaram ou não utilizaram & 13 & 30,23 & 100,0 \\
\hline Total & $\mathbf{4 3}$ & $\mathbf{1 0 0 , 0}$ & \\
\hline
\end{tabular}

Fonte: Elaborada pelos autores.

Já como proxy do ativo livre de risco, a maioria baseou-se no CDI, representando quase $28 \%$ dos artigos, seguido da SELIC (aproximadamente 19\%), e da caderneta de poupança (10\%). Diferentes alternativas foram: CDI-acumulado, OTN, BTN, para os dados nacionais. Com relação aos dados internacionais, utilizou-se a prime rate-USA e T-Bonds. Cabe salientar que a maior parte dos autores não apresentou um embasamento para a utilização de determinada taxa, o que indicaria a sua adequação ao modelo, o que talvez comprometeria sua aplicação. Segundo Silveira, Barros e Famá (2002), escolher uma taxa livre de risco, no Brasil, é um problema, pois inexiste uma taxa correspondente totalmente ajustada à teoria do CAPM. Entretanto, Silva, Melo e Pinto (2009) justificam a utilização da poupança por se tratar de uma aplicação financeira em que os retornos históricos apresentam desvio-padrão mais baixo, o que significa baixa variação nos mesmos, tornando-se uma referência mais apropriada para o ativo em questão, além de ser acessível a qualquer investidor, conforme sugerem Sanvicente e Minardi (1998) e Damodaran (2002).

$\mathrm{Na}$ escolha do ativo livre de risco, o que vem sendo recomendado é que seu prazo de vencimento seja idêntico ao do período de investimento (BRUNI, 1998), o que torna mais apropriada sua utilização. Entretanto, a utilização do CDI é criticada por não ser acessível aos investidores privados, visto que é negociado apenas entre instituições bancárias. Da mesma forma, a SELIC, enquanto taxa básica de remuneração da economia, constitui o custo que essas instituições têm para obter recursos junto ao BACEN e, por isso, também, não é acessível aos investidores. Quanto aos deflacionadores de dados, a maior parte dos autores optou pelo IGP- 
DI - cerca $12 \%$ dos artigos. IGP-M e IPCA/FGV foram menos utilizados.

Tabela 10: Tipos de ações

\begin{tabular}{c|c|c|c}
\hline Tipo de ações & Quantidade & $\mathbf{\%}$ & \% acumulado \\
\hline ON e PN & 10 & 23,26 & 23,26 \\
\hline Não informaram & 27 & 62,79 & 86,05 \\
\hline Não utilizaram & 6 & 13,95 & 100,0 \\
\hline Total & $\mathbf{4 3}$ & $\mathbf{1 0 0 , 0}$ & \\
\hline
\end{tabular}

Fonte: Elaborada pelos autores.

Em quase $63 \%$ dos trabalhos o tipo de ações utilizadas não foi apontado. Nesses casos, acredita-se que foram estudadas tanto ações ON como PN. Porém, isso pode gerar erro ou impossibilitar a reprodução da pesquisa. Por outro lado, alguns autores estudaram o desempenho de fundos e, de certo modo, talvez não fosse tão importante saber se eram ações $\mathrm{ON}$ ou PN, o que poderia justificar a não descrição do tipo de ação na metodologia. E, uma parcela dos autores que, de alguma maneira, estudaram o CAPM, não se utilizou de ações - em torno de $14 \%$ da amostra.

Tabela 11: Períodos estudados (anos)

\begin{tabular}{c|c|c|c}
\hline Quantidade de anos & Quantidade & $\mathbf{\%}$ & \% acumulado \\
\hline Quatro & 5 & 11,63 & 11,63 \\
\hline Cinco & 4 & 9,30 & 20,93 \\
\hline Seis & 4 & 9,30 & 30,23 \\
\hline Oito & 4 & 9,30 & 39,53 \\
\hline Sete & 3 & 6,98 & 46,51 \\
\hline Dez & 3 & 6,98 & 53,49 \\
\hline Doze & 3 & 6,98 & 60,47 \\
\hline Vinte ou mais & 3 & 6,98 & 67,44 \\
\hline Outros períodos & 11 & 25,58 & 93,02 \\
\hline Não utilizaram & 3 & 6,98 & 100,0 \\
\hline Total & $\mathbf{4 3}$ & $\mathbf{1 0 0 , 0 0}$ &
\end{tabular}

Fonte: Elaborada pelos autores.

Em relação aos períodos estudados, houve maior frequência para artigos com análises de quatro, cinco, seis e oito anos, correspondendo a quase $40 \%$ do total. Logo depois, os estudos de dez e doze anos representaram aproximadamente 14\%. Além disso, foram estudados três artigos com análises de vinte anos ou mais, o equivalente a algo próximo a $7 \%$ da amostra. Constatou-se que, em média, os autores buscaram extrair suas conclusões sobre o desempenho do CAPM e outros modelos, por um período abaixo de dez anos. Isso pode ser explicado por Bruni (1998), pois o mesmo cita haver enorme dificuldade na obtenção de dados financeiros do país para a um período mais amplo, o que pode ocasionar problemas nas conclusões e validade dos estudos.

Tabela 12: Abordagem individual ou portfolio

\begin{tabular}{c|c|c|c}
\hline Abordagem & Quantidade & $\mathbf{\%}$ & \% acumulado \\
\hline Individuais & 19 & 44,19 & 44,19 \\
\hline Portfolio & 17 & 39,53 & 83,72 \\
\hline Não se aplica & 7 & 16,28 & 100,0 \\
\hline Total & $\mathbf{4 3}$ & $\mathbf{1 0 0 , 0}$ & \\
\hline
\end{tabular}

Fonte:Elaborada pelos autores. 
Foi possível verificar que a maioria dos autores preferiu estudar a precificação de ativos, sobretudo, por intermédio do CAPM, com ativos individuais. Mas, cerca de $40 \%$ o fez por meio de portfolios de ações, ou de fundos de investimento cambial, multimercado ou renda fixa. Outros $14 \%$ da amostra não se utilizaram dessas abordagens.

Tabela 13: Cruzamento de variáveis $x$ artigos convergentes e divergentes

\begin{tabular}{|c|c|c|c|c|}
\hline & Artigos convergentes & $\%$ & $\begin{array}{c}\text { Artigos } \\
\text { convergentes }\end{array}$ & $\%$ \\
\hline \multicolumn{5}{|c|}{ Completude dos dados informados na metodologia } \\
\hline Dados informados completamente & 16 & 64,0 & 12 & 66,7 \\
\hline Não informaram & 2 & 8,0 & 1 & 5,6 \\
\hline Dados informados incompletos & 7 & 28,0 & 5 & 27,8 \\
\hline Total & 25 & 100,0 & 18 & 100,0 \\
\hline \multicolumn{5}{|c|}{ Tipos de análise } \\
\hline Cross-section & 22 & 88,0 & 15 & 83,3 \\
\hline Panel Data & 1 & 4,0 & 1 & 5,6 \\
\hline Cross-section e Panel Data & 0 & 0,0 & 1 & 5,6 \\
\hline Questionário & 1 & 4,0 & 1 & 5,6 \\
\hline Ensaio-teórico & 1 & 4,0 & 0 & 0,0 \\
\hline Total & 25 & 100,0 & 18 & 100 \\
\hline \multicolumn{5}{|c|}{ Proxies da carteira de mercado } \\
\hline Ibovespa & 13 & 52,0 & 8 & 44,4 \\
\hline FGV-100 & 1 & 4,0 & 2 & 11,1 \\
\hline IBRX & 1 & 4,0 & 1 & 5,6 \\
\hline Criada por autores & 2 & 8,0 & 1 & 5,6 \\
\hline Outras & 5 & 20,0 & 1 & 5,6 \\
\hline Total & 22 & 88,0 & 13 & 72,2 \\
\hline \multicolumn{5}{|c|}{ Proxies do ativo livre de risco } \\
\hline CDI & 4 & 16,0 & 8 & 44,4 \\
\hline SELIC & 6 & 24,0 & 2 & 11,1 \\
\hline Poupança & 3 & 12,0 & 1 & 5,6 \\
\hline Outros & 4 & 16,0 & 2 & 11,1 \\
\hline Não informaram ou não utilizaram & 9 & 36,0 & 4 & 22,2 \\
\hline Total & 26 & 104,0 & 17 & 94,4 \\
\hline \multicolumn{5}{|c|}{ Períodos estudados (anos) } \\
\hline Quatro & 5 & 20,0 & 0 & 0,0 \\
\hline Cinco & 2 & 8,0 & 1 & 5,6 \\
\hline Seis & 3 & 12,0 & 3 & 16,7 \\
\hline Oito & 1 & 4,0 & 2 & 11,1 \\
\hline Sete & 1 & 4,0 & 2 & 11,1 \\
\hline Dez & 3 & 12,0 & 1 & 5,6 \\
\hline Doze & 1 & 4,0 & 1 & 5,6 \\
\hline Vinte ou mais & 0 & 0,0 & 2 & 11,1 \\
\hline Outros períodos & 7 & 28,0 & 6 & 33,3 \\
\hline Não estudaram períodos & 2 & 8,0 & 0 & 0,0 \\
\hline Total & 25 & 100,0 & 18 & 100,0 \\
\hline
\end{tabular}

Fonte: Elaborada pelos autores. 
No cruzamento de algumas variáveis investigadas com os artigos que confirmaram ou refutaram a eficiência do modelo CAPM, aproximadamente $28 \%$ de ambos os trabalhos - sugerindo um empate técnico - informaram os dados de forma incompleta. Assim, não se pode supor que esse fato seja influente para criticar a efetividade da teoria do CAPM, no Brasil. Quanto ao tipo de análise, $88 \%$ dos artigos convergentes e pouco mais de $83 \%$ dos divergentes realizaram cross-section, o que tampouco permite afirmar que tenha provocado efeitos diferentes.

No que tange às proxies da carteira de mercado, $52 \%$ dos trabalhos que corroboraram a teoria, e aproximadamente $44 \%$ dos que sinalizaram sua ineficiência, utilizaram o Ibovespa. Logo, mesmo que seja indicada como uma proxy inapropriada para seu fim (um índice concentrado em poucos ativos), na amostra analisada esse fato parece contribuir mais para confirmar a eficiência do CAPM, no Brasil, que o contrário.

Eentre as pesquisas que revelaram qual a proxy do ativo livre de risco aplicada, a maioria dos convergentes (24\%) baseou-se na SELIC, seguida do CDI e da poupança (ambos com 16\%), estas criticadas por serem inacessíveis ao investidor privado. Naqueles que refutaram o CAPM, prevaleceu, com aproximadamente $44 \%$, a utilização do CDI. Dessa maneira, percebe-se que, a maioria dos artigos preferiu o CDI, e não a poupança - apontada como a mais adequada para estudos desse tipo no Brasil (e.g. Silva, Melo e Pinto, 2009). Entretanto, mesmo inexistindo uma proxy totalmente ajustada à teoria do modelo, vários testes com as mesmas confirmaram o desempenho positivo do CAPM ao utilizá-las. Por outro lado, entre as pesquisas que refutaram a teoria, predominou a aplicação do CDI, o que pode ter auxiliado para que isso acontecesse, mas não se sabe se outros fatores contribuíram também.

No que se refere aos períodos estudados, nos artigos convergentes prevaleceram "outros períodos" $(28 \%)$, que abarcaram testes de um a três anos, seguido de quatro anos $(20 \%)$, e apenas $16 \%$ dos trabalhos investigaram períodos mais longos como a partir de dez anos (16\%). Portanto, na maioria deles, não foi preciso realizar trabalhos sobre períodos longos para corroborar o modelo. Por outro lado, nas pesquisas divergentes os "outros períodos" (aproximadamente 33\%) prevaleceu, os artigos referentes a seis anos foram quase 17\%, e cerca de $11 \%$ dos trabalhos abordou períodos bastante longos, vinte anos ou mais. E, se por um lado há insuficiência de bases de dados referentes a períodos extensos, por outro, o fato de os testes com períodos menores poderem aumentar a eficiência das regressões (e.g. Bruni, 1998), podem ter favorecido a preferência dos pesquisadores, pois seu manuseio é mais simples. Contudo, mesmo nas análises com períodos mais amplos, ou mais curtos, houve refutação do CAPM.

\section{CONSIDERAÇÕES FINAIS}

Esta pesquisa procurou fazer um levantamento dos artigos acadêmicos abordando o modelo CAPM e variantes, no país, entre 1997 e 2008, nos EnANPADs e em periódicos nacionais, para conhecer suas principais características metodológicas e constatações.

Por meio deste levantamento referente às pesquisas que empreenderam análises teóricas e, sobretudo, empíricas sobre o modelo CAPM e suas variantes, foi possível verificar como os autores têm abordado esse objeto de estudo, com quais métodos, quais tipos de dados, tipos de análise preferidos, testes efetuados, tipos de ações, média de períodos analisados, análises de 
ativos individuais ou de portfolios, bem como se as conclusões dessas pesquisas convergem para a teoria do CAPM ou se a contestam.

A partir disso, foram identificados os seguintes perfis das pesquisas analisadas: para os trabalhos que confirmaram a efetividade da teoria: i) boa parte informou os dados incompletos; ii) prevaleceram as análises cross-section; iii) o Ibovespa foi a proxie da carteira de mercado mais utilizada; iv) a proxie do ativo livre de risco SELIC foi a preferida; v) os períodos dos dados entre um e três anos foram os predominantes nos testes. Já nas pesquisas que refutaram a teoria: i) a maioria revelou os dados incompletos; ii) houve predomínio das análises crosssection; iii) a carteira do Ibovespa foi a preferida; iv) o CDI foi a proxie do ativo livre de risco mais utilizada; v) destacaram-se os períodos de um a três anos.

Algumas pesquisas sobre o CAPM, no país, são "superficiais" em termos metodológicos, sobretudo aquelas publicadas no EnANPAD, pois, ao que parece, os pesquisadores não realizam os testes necessários, a pesquisa não pode ser replicada e os resultados carecem de validade, não cumprindo o rigor científico necessário. Entretanto, como os trabalhos de eventos estão (em tese) ainda em discussão, a crítica é parcialmente válida. Como era de se esperar, notou-se um maior rigor nas pesquisas publicadas em periódicos.

Por outro lado, as constatações apontam a existência de problemas na avaliação da pesquisa na área, no Brasil, visto que, aparentemente, os avaliadores desses trabalhos podem não estar tomando os devidos cuidados em suas avaliações (ou pior, não conhecem o assunto como deveriam, para poderem avaliar a pesquisa).

Como caráter de conclusão, de forma geral, o modelo tem apresentado desempenho satisfatório no mercado brasileiro, apesar dos desajustes decorrentes da indisponibilidade de dados para certos períodos, da inadequação, apontada pela literatura, das proxies da carteira de mercado e do ativo livre de risco, do mercado brasileiro, para a realização de testes empíricos da teoria. Dessa maneira, as anomalias apontadas não estariam na teoria, e sim, na sua operacionalização. Com isso, tem-se buscado comparar seu desempenho com outros modelos, ou acrescentar fatores que ampliem seu poder de predição do retorno de ativos, para a obtenção de um apreçamento mais adequado para o esse mercado. E, ainda que os modelos sofisticados possam apresentar um desempenho superior, os usuários podem preteri-los, por ser mais complexa sua operacionalização, realizando avaliações imprecisas, aquém das ferramentas disponíveis.

Como contribuição, considerando-se o desenvolvimento do mercado bursátil brasileiro, acredita-se que tal levantamento sobre a pesquisa da pesquisa acerca do CAPM e variantes poderá auxiliar no avanço dos entendimentos sobre o panorama da pesquisa acadêmica produzida sobre o modelo, bem como sobre as avaliações das mesmas, conferindo subsídios para a elaboração de outros testes empíricos, e para a melhoria das avaliações, impedindo que os pesquisadores não caiam nas "armadilhas da pesquisa sobre o mesmo". Ele também fornece um resumo conceitual/teórico sobre o que tem sido desenvolvido sobre o tema, contribuindo para os iniciantes/novatos pouco ou nada familiarizados com ele, podendo ainda ser utilizado para fins didáticos.

A restrição da amostra em artigos nacionais e em somente um congresso, com foco apenas no modelo CAPM, constitui uma limitação do trabalho. Como sugestão para pesquisas futuras, a amostra poderia ser maior, com artigos nacionais e internacionais, sobre outros modelos de apreçamento de ativos, e outros meios de comunicação acadêmica. Com isso, haveria uma 
comparação com os dados de artigos internacionais, proporcionando resultados mais robustos, e apresentando o grau de influência destes nos artigos brasileiros, o que enriqueceria as conclusões aqui apresentadas, bem como as análises de outros modelos de precificação que vêm sendo testados.

\section{REFERÊNCIAS}

AMARAL, H. F.; VILAÇA, C. S. I.; BARBOSA, C. F. M.; FULLY BRESSAN, V. G. Fundos de pensão como formadores de poupança interna: uma alternativa para o financiamento da atividade econômica. Revista de Administração Contemporânea, v. 8, n. 2, abr./jun., 2004.

ARAÚJO, D. L.; BRESSAN, A. A.; BERTUCCI, L. A. Análise do risco de mercado do agronegócio brasileiro: um estudo comparativo entre os modelos CAPM e GARCH-M. In: Encontro da Associação Nacional de Pós-graduação e Pesquisa em Administração, 28., 2004, Curitiba (PR). Anais... Rio de Janeiro: ANPAD, 2004.

BARBOSA, T.; MOTTA, L. Custo de capital próprio em mercados emergentes: CAPM x D-CAPM. Revista Eletrônica de Gestão e Organização, v. 2, n. 3, 2004.

BAWA, V.; LINDENBERG, E. Capital market equilibrium in a mean-lower partial moment framework, Journal of Financial Economics, v. 5, p. 189-200, 1977.

BANZ, R. The relationship between return and market value of common stocks. Journal of Financial Economics, v. 9, p. 3-18, 1981.

BASU, S. Investment performance of common stock in relation to their price-earnings rations: a test of market efficiency, Journal of Finance, v. 32, p. 3-18, 1977.

BLACK, F. Capital market equilibrium with restricted borrowing, Journal of Business, v. 45, p. 444-455, 1972.

, JENSEN, M. C.; SCHOLES, M. The capital asset pricing model: some empirical tests. In: JENSEN, M. C. (Ed), Studies in the Theory of Capital Markets. New York: Praeger, 1972.

BLUME, M.; FRIEND, I. A new look at capital asset pricing model, Journal of Finance, v. 28, p. 19-33, 1973.

BREEDEN, D. An intertemporal asset pricing model with stochastic consumption and investment opportunities, Journal f Financial Economics, v. 7, p. 265-296, 1979.

BRUNI, A. L. Risco, retorno e equilíbrio: uma análise do modelo de precificação de ativos financeiros na avaliação de ações negociadas na Bovespa (1988-1996). Dissertação de Mestrado. Faculdade de Economia, Administração e Contabilidade da Universidade de São Paulo, 1998.

CAMPBELL, J. Y. (1993). Intertemporal asset pricing without consumption data. American Review, v. 83, n. 3, p. 487-512, Jun., 1993. 
CASOTTI, F. P.; MOTTA, L. F. J. Oferta pública inicial no Brasil (2004-2006): uma abordagem da avaliação através de múltiplos e do custo de capital próprio. Revista Brasileira de Finanças, v. 6, n. 2, p. 157-204, 2008.

CASTRO Jr., F. H. F.; YOSHINAGA, C. E. Influência de comomentos em modelos de precificação: um estudo empírico com dados em painel. In: Encontro da Associação Nacional de Pós-graduação e Pesquisa em Administração, 32., 2008, Rio de Janeiro (RJ). Anais... Rio de Janeiro: ANPAD, 2008.

CAstro Silva, W. A. C.; PINTO, E. A.; MElO, A. O.; CAMARGOS, M. A. Análise comparativa entre o CAPM e o C-CAPM na precificação de índices acionários: evidências de mudanças nos coeficientes estimados de 2005 à 2008. In: Encontro Brasileiro de Finanças, 9., 2009, São Leopoldo. Anais... São Paulo: SBFIN, 2009.

; MELO, A. O.; PINTO, E. A. Capital asset pricing model (CAPM) e variantes em apreçamento de índices acionários da bolsa de valores de São Paulo. In: Encontro Nacional de Engenharia de Produção, 29., 2009, Salvador. Anais... Rio de Janeiro: ABEPRO, 2009.

CERETTA, P. S.; COSTA JÚNIOR., N. C. A. Performance ajustada aos diversos níveis de risco. In: Encontro da Associação Nacional de Pós-graduação e Pesquisa em Administração, 22., 1998, Foz do Iguaçu (PR). Anais... Rio de Janeiro: ANPAD, $1998 .$.

, P. S.; CATARINA, G. F. S.; MULLER, I. Modelo de precificação incorporando assimetria e curtose sistemática. In: Encontro da Associação Nacional de Pós-graduação e Pesquisa em Administração, 31., 2007, Rio de Janeiro (RJ). Anais... Rio de Janeiro: ANPAD, 2007.

CHEN, N.; ROLL, R.; ROSS, S. Economic forces and the stock markets. Journal of Business, v. 59, p. 386-403, Jul., 1986.

COCHRANE, J. H. A cross-sectional test of an investment-based asset pricing model, Journal of Political Economy, v. 104, p. 572-621, 1996.

COLLIS, J.; HUSSEY, R. Pesquisa em administração: um guia prático para alunos de graduação e pós-graduação. 2. ed. Porto Alegre: Bookman, 2005.

COSTA JR., N. C. A.; MENEZES, E. A.; LEMGRUBER, E. F. Estimação do beta de ações através do método dos coeficientes agregados. Revista Brasileira de Economia, Rio de Janeiro: v. 47, n. 4, p. 605-621, out./dez., 1993.

DAMODARAN, A. Investment Valuation: tools and techniques for determining the value of any asset. 2. ed. New York: Wiley, 2002.

DOUGLAS, G. W. W. Risk in the equity markets: an empirical appraisal of market efficiency. Yale Economic Essays, v. 9, n. 1, p. 3-45, 1969.

DURACK, N.; DURAND, R.B.; MALLER, R. A. A best choice among asset pricing models? The conditional capital asset pricing model in Australia. Accounting and Finance, Carlton, v. 44, n. 2, p. 139-162, Jul., 2004.

ENCONTRO DA ASSOCIAÇÃO NACIONAL DE PÓS-GRADUAÇÃO E PESQUISA EM ADMINISTRAÇÃO (ANPAD). Disponível em: http://www.anpad.org.br/index.php. Acesso 
em: 09 jan 2010 .

ESTRADA, J. The cost of equity in emerging markets: a downside risk approach. Emerging Marketing Quarterly, New York, v. 3, n. 1, p. 19-30, 2000.

. Systematic risk in emerging marketing: the D-CAPM. Emerging Markets Review, New York, v. 3, p.365-379, 2002.

FERSON, W. E.; HARVEY, C. R. The variation of economic risk premiums. Journal of Political Economy, New York, v. 99, p. 385-415, 1991.

FAMA, E. F. Efficient capital markets: a review of theory and empirical work. The Journal of Finance, v. 25, n. 2, p. 383-417, May, 1970.

; MACBETH, J. D. Risk, return and equilibrium: empirical tests. Journal of Political Economy, v. 8, n. 3, p. 607-636, May/Jun., 1973.

FAMA, E. F. Efficient capital markets II. The Journal of Finance, v. 46, n. 5, p. 575-617, Dec., 1991.

; FRENCH, K. R. The cross-section of expected stock returns. Journal of Finance, v. 47, n. 2, p. 427-466, 1992.

GALDI; F. C.; SECURATO, J. R. O risco idiossincrático é relevante no mercado brasileiro? Revista Brasileira de Finanças, v. 5, n. 1, p. 41-58, 2007.

GARRÁN, F. T.; MARTELANC, R. Metodologias em uso no Brasil para determinação do custo de capital próprio. In: Encontro da Associação Nacional de Pós-graduação e Pesquisa em Administração, 31., 2007, Rio de Janeiro (RJ). Anais... Rio de Janeiro: ANPAD, 2007.

HANSEN, L.; SINGLETON, K. Stochastic consumption, risk aversion, and the temporal behavior of asset returns. Journal of Political Economy, v. 91, p. 249-268, 1983.

HANSEN, L.; RICHARD, S. The role of conditioning information in deducing testable restrictions implied by dynamic asset pricing models. Econometrica, v. 55, p. 587-613, 1987.

HARVEY, C.; SIDDIQUE, A. Autoregressive conditional skewness. Journal of Financial and Quantitative Analysis, v. 34, p. 465-88, 1999.

HAUGEN, R. A. Modern investment theory. 5. ed. New Jersey: Prentice-Hall, 2001.

JAGANNATHAN, R.; WANG, Z. The conditional CAPM and the cross-section of expected returns. Journal of Finance, v. 51, n. p-53, Mar., 1996.

LAKONISHOK, J.; SHLEIFER, A.; VISHNY, R. W. Contrarian investment, extrapolation, and risk. Journal of Finance, p. 1541-1579, Dec., 1994.

LEWENLlEN, J.; NEGEL, S. The conditional CAPM does not explain asset-pricing anomalies. (Working Paper, 9974), 2003. Disponível em: http://www.nber.org/paper/w9974.

LINS, A. G.; SILVA, W. V.; GOMES, L.; MARQUES, S. Formulação de carteiras hipotéticas de ativos financeiros usando a técnica de análise de cluster. In: Encontro da Associação Nacional 
de Pós-graduação e Pesquisa em Administração, 31., 2007, Rio de Janeiro (RJ). Anais... Rio de Janeiro: ANPAD, 2007.

LINTNER, J. The valuation of risk asset an the selection of risk investments in stock portfolio and capital budgets. Review of Economics and Statistics, v. 47, n. 1, p. 13-37, 1965.

LUCAS, R. Asset prices in an exchange economy. Econometrica, v. 46, p. 1429-1445, 1978.

MANTOVANINI, R. E. M.; BERTUCCI, L. A.; BRESSAN, A. A. A relação risco-retorno: avaliação de um modelo comportamental no mercado acionário brasileiro. In: Encontro da Associação Nacional de Pós-graduação e Pesquisa em Administração, 27., 2003, Atibaia (SP). Anais... Rio de Janeiro: ANPAD, 2003.

MAYERS, D. Nonmarketable assets and capital markets equilibrium under uncertainty. In: JENSEN, M. C. Studies in the Theory or Capital Markets. New York: Praeger, 1972.

MARKOWITZ, H. M. Portfolio selection. Journal of Finance, New York, v. 7, n. 1, p. 77-91, Mar., 1952.

MARKOWITZ, H. M. Portfolio selection: efficient diversification of investment. Journal of Finance, New York: Wiley, 1959.

MATTOS, A. E. K.; KUDE, B.; VITIELLO JÚNIOR., L. R. S.; GAVA, A. M. O desempenho condicional e não condicional dos fundos mútuos brasileiros: 1993-1996. In: Encontro da Associação Nacional de Pós-graduação e Pesquisa em Administração, 21., 1997, Rio das Pedras (RJ). Anais... Rio de Janeiro: ANPAD, 1997.

MAZER, L. P.; NAKAO, S. H. O impacto do nível de transparência no custo do capital proprio das empresas do Ibovespa. In: Encontro da Associação Nacional de Pós-graduação e Pesquisa em Administração, 32., 2008, Rio de Janeiro (RJ). Anais... Rio de Janeiro: ANPAD, 2008.

MERTON, R. C. An intertemporal capital asset pricing model. Econometrica, v. 41, n. 5, p. 867-887, Sept., 1973.

MODIGLIANI, F.; MILLER, M. H. The cost of capital, corporate finance and the theory of investiment. The American Economic Review, v. 48, n. 3, p. 261-97, June, 1958.

Corporate income taxes and the cost of capital: a correction. American

Economic Review, v. 53, n. 3, p. 433-43, 1963.

MOORE, D. S. A estatística básica e sua prática. 3.ed. Rio de Janeiro: LTC, 2005.

MOSSIN, J. Equilibrium in a asset market. Econometria, v. 34, n . 4, p. 768-783, 1966.

MOTTA, L. F. J.; FORTUNATO, G.; RUSSO, G. Custo de capital próprio em mercados emergentes: resultados de uma investigação empírica no Brasil com o Downside Risk. In: Encontro da Associação Nacional de Pós-graduação e Pesquisa em Administração, 31., 2007, Rio de Janeiro (RJ). Anais... Rio de Janeiro: ANPAD, 2007.

NEVES, A. W.; AMARAL, H. F. A precificação de ativos de renda variável no mercado de capitais brasileiro: uma visão comparativa entre a Arbitrage Pricing Theory e o Capital Asset Pricing Model. In: Encontro da Associação Nacional de Pós-graduação e Pesquisa em 
Administração, 26., 2002, Salvador (BA). Anais... Rio de Janeiro: ANPAD, 2002.

PILOTO, L. A. M.; SENRA, L. F. A. C.; MORENO, R.. Adaptação do WACC ao juros sobre capital próprio. In: Encontro da Associação Nacional de Pós-graduação e Pesquisa em Administração, 32., 2008, Rio de Janeiro (RJ). Anais... Rio de Janeiro: ANPAD, 2008.

RABELO, S. S. T.; ROGERS, P.; RIBEIRO, K. C. S.; MENDES-DA-SILVA, W. Performance das melhores práticas de governança corporativa no Brasil: um estudo de carteiras. In: Encontro da Associação Nacional de Pós-graduação e Pesquisa em Administração, 31., 2007, Rio de Janeiro (RJ). Anais... Rio de Janeiro: ANPAD, 2007.

RABONI, P. L.; SILVANETO, O. S.; MARANHÃO, V.L.A.;ARAÚJOFILHO, L. F. C. Testando um "mito de investimento": eficácia da estratégia de investimento em ações de crescimento. In: Encontro da Associação Nacional de Pós-graduação e Pesquisa em Administração, 32., 2008, Rio de Janeiro (RJ). Anais... Rio de Janeiro: ANPAD, 2008.

REINGANUM, M. R. Misspecification of capital asset pricing: empirical anomalies based on earnings yields and market values. Journal of Financial Economics, v. 9, p. 19-46, 1981.

RIBENBOIM, G. Teste do modelo CAPM com dados Brasileiros. In: BONOMO, M. A. (Org.). Finanças aplicadas ao Brasil. 2. ed. Rio de Janeiro: FGV, 2004.

ROCHMAN, R. R.; EID Jr, W. Fundos de investimento ativos e passivos no Brasil: comparando e determinando os seus desempenhos. In: Encontro da Associação Nacional de Pós-graduação e Pesquisa em Administração, 30., 2006, Salvador (BA). Anais... Rio de Janeiro: ANPAD, 2006.

ROGERS, P.; SECURATO, J. R. Estudo comparativo no mercado brasileiro do Reward Beta Approach, Capital Asset Princing Model (CAPM) e Modelo 3-Fatores de Fama e French In: Encontro da Associação Nacional de Pós-graduação e Pesquisa em Administração, 32., 2008, Rio de Janeiro (RJ). Anais... Rio de Janeiro: ANPAD, 2008.

ROSTAGNO, L. M.; KLOECKNER, G. O.; BECKER, J. L. Previsibilidade de retorno das ações na Bovespa: um teste envolvendo o modelo de fator de retorno esperado. Revista Brasileira de Finanças, v. 2, n. 2, 2005.

SAITO, R.; BUENO, R. L. S. Fundamentos teóricos e empíricos de apreçamento de ativos. Revista de Administração de Empresas, v. 47, n. 2, p. 81-5, abr. / jun. 2007.

SALMASI, S. V. Governança corporativa e custo de capital próprio no Brasil. In: ENANPAD, 32., 2008, Rio de Janeiro (RJ). Anais... Rio de Janeiro: ANPAD, 2008.

SANVICENTE, A. Z.; MINARDI, A. M. A. F. Qual é a taxa de desconto adequada para avaliar as ações da Telebrás? IBMEC, Relatório de Pesquisa, jun. 1998. Disponível em: http:// ibmecsp.edu.br/pesquisa/templates/pesquisa/docs/telebras.pdf. Acesso em: 09 jul. 2010.

SECURATO, J. R. Decisões financeiras sob condições de risco. São Paulo: Atlas, 1996.

SHARPE, W. F. A simplified model for portfolio analysis. Management Science, Eldridge, v. 9, n. 2, p. 277-293, Jan., 1963.

Capital Asset Prices: A theory of market equilibrium under conditions of risk. Journal of Finance, v. 19, p. 425-42, Sept., 1964. 
Hall, 1995.

, ALEXANDER, G. J.; BAILEY, J. V. Investments. 5. ed. New Jersey: Prentice

SILVA, S. Precificação de ativos com risco no mercado acionário brasileiro: aplicação do modelo CAPM e variantes. 144p. Dissertação (Mestrado) - Universidade Federal de Lavras, Lavras, 2007.

SILVA, C. A. T.; MUNHOZ, D. A. A utilização do lucro contábil como proxy do risco no Brasil. In: Encontro da Associação Nacional de Pós-graduação e Pesquisa em Administração, 30., 2006, Salvador (BA). Anais... Rio de Janeiro: ANPAD, 2006.

SILVEIRA, H. P.; BARROS, L. A. B. C.; FAMÁ, R. Conceito de taxa livre de risco e sua aplicação no capital asset pricing model - um estudo exploratório para o mercado brasileiro. In: Encontro Brasileiro de Finanças, 2., 2002, Rio de Janeiro. Anais... São Paulo: SBFIN, 2002.

SOARES, R. O.; ROSTAGNO, L. M.; SOARES, K. T. C. Estudo de evento: o método e as formas de cálculo do retorno anormal. In: Encontro da Associação Nacional de Pós-graduação e Pesquisa em Administração, 26., 2002, Salvador (BA). Anais... Rio de Janeiro: ANPAD, 2002.

TAMBOSI FILHO, E.; COSTA JÚNIOR, N. C. A.; ROSSETTO, J. R. Testando o CAPM condicional nos mercados brasileiro e norte-americano. Revista de Administração Contemporânea, v. 10, n. 4, p. 143-168, out./dez., 2006.

TOBIN, J. Liquidity preference as a behavior toward risk. Review of Economic Studies, p. 65-86, 1958.

TOMAZONI, T.; MENEZES, E. A. Estimativa do custo de capital de empresas brasileiras de capital fechado (sem comparáveis de capital aberto). Revista de Administração da USP, v. 37 , n. 4, p. 38-48, out./dez., 2002.

TREYNOR, J. L. Toward a theory of market value of risky assets. No press, 1961.

ZIMMERMANN, C. C.; LEMME, C. F. Avaliação de empresas, custo do capital próprio e modelagem financeira: um estudo no setor de distribuição de eletricidade brasileiro no período de 1995 a 2000. In: Encontro da Associação Nacional de Pós-graduação e Pesquisa em Administração, 27., 2003, Atibaia (SP). Anais... Rio de Janeiro: ANPAD, 2003. 


\section{DADOS DOS AUTORES:}

\section{ELISSON ALBERTO TAVARES ARAÚJO}

Fundação Dom Cabral.

Bernardo Guimarães, 3071 - Barro Preto

30140-083 - Belo Horizonte, MG - Brasil

\section{VICTOR DO CARMO OLIVEIRA}

Faculdade ASA - Instituição Educacional Cecília Maria de Melo Barcelos.

MG 040 S/N BRUMADINHO/MG

35460-000 - Brumadinho, MG - Brasil

\section{WENDEL ALEX CASTRO SILVA}

Faculdade Novos Horizontes.

Rua Alvarega Peixoto, 1270 - Santo Agostinho

30180-121 - Belo Horizonte, MG - Brasil 